\title{
ARTIFICIAL NEURAL NETWORKS PRUNING APPROACH FOR GEODETIC VELOCITY FIELD DETERMINATION
}

\author{
Redes Neurais Artificiais aplicadas para a determınação de campo de velocidades \\ em Geodésia
}

\section{MUSTAFA YILMAZ}

Department of Geomatics, Faculty of Engineering, Afyon Kocatepe University ANS Campus, Gazligol Road, Afyonkarahisar - Turkey.

E-mail: mustafayilmaz@aku.edu.tr

\begin{abstract}
There has been a need for geodetic network densification since the early days of traditional surveying. In order to densify geodetic networks in a way that will produce the most effective reference frame improvements, the crustal velocity field must be modelled. Artificial Neural Networks (ANNs) are widely used as function approximators in diverse fields of geoinformatics including velocity field determination. Deciding the number of hidden neurons required for the implementation of an arbitrary function is one of the major problems of ANN that still deserves further exploration. Generally, the number of hidden neurons is decided on the basis of experience. This paper attempts to quantify the significance of pruning away hidden neurons in ANN architecture for velocity field determination. An initial back propagation artificial neural network (BPANN) with 30 hidden neurons is educated by training data and resultant BPANN is applied on test and validation data. The number of hidden neurons is subsequently decreased, in pairs from 30 to 2, to achieve the best predicting model. These pruned BPANNs are retrained and applied on the test and validation data. Some existing methods for selecting the number of hidden neurons are also used. The results are evaluated in terms of the root mean square error (RMSE) over a study area for optimizing the number of hidden neurons in estimating densification point velocity by BPANN.

Keywords: Artificial Neural Networks; Pruning Hidden Neurons; Geodetic Point Velocity.
\end{abstract}




\section{RESUMO}

A densificação de redes geodésicas é uma necessidade presente desde o início das atividades de levantamentos. Para a obtenção de resultados adequados a modelagem de campos de velocidades da crosta deve ser efetivada. Redes Neurais Artificiais (RNAs) são amplamente utilizadas como aproximadores de funções em diversas aplicações em Geomática, incluindo a determinação campos de velocidade. Decidir o número de neurônios ocultos necessários à implementação de uma função arbitrária é um dos principais problemas de RNA que ainda merece destaque nas Ciências Geodésicas. Geralmente, o número de neurônios ocultos é decidido com base na experiência do usuário. Com estas considerações em mente, surgem métodos de determinação automática de arquiteturas de RNAs, como os Métodos de Poda. Neste artigo busca-se quantificar a importância de poda ou supressão de neurônios ocultos em uma arquitetura de RNA para determinar o campo de velocidades. Uma RNA com retro-propagação contendo 30 neurônios ocultos é treinada e testes são aplicados. O número de neurônios ocultos é reduzido de trinta até dois, dois a dois, visando-se encontrar a melhor arquitetura de predição. Também são utilizados alguns métodos existentes para a escolha do número de neurônios ocultos. Os resultados são avaliados em termos raiz do erro médio quadrático ao longo de uma área de estudo para otimizar o número de neurônios ocultos na estimativa de velocidades com base na densificação de pontos com a RNA.

Palavras-chave: Redes Neurais Artificiais; Poda de Neurônios Ocultos; Velocidades de Pontos Geodésicos.

\section{INTRODUCTION}

There has been a need for geodetic network densification since the early days of traditional surveying. The general objective of network densification is to provide a more convenient accurate access to the reference frame (FERLAND et al., 2002). The densification of the geodetic networks is necessary in support of large-scale mapping applications, cadastral measurement and geodetic point construction. Nowadays, the Global Positioning System (GPS) is most frequently used to densify geodetic networks. Densifying the geodetic networks in Turkey require determining the positions of potential new GPS sites with reference to the locations of existing GPS sites (TURKISH CHAMBER OF SURVEY AND CADASTRE ENGINEERS, 2008). Therefore, it is necessary to estimate the velocity vectors of the densification points in order to obtain the associated coordinates with the reference GPS epoch.

The geodetic point velocities derived from measured time series of GPS sites are used as basic parameter in geodetic and geophysical applications, including velocity field determination of geodetic networks, kinematic modelling of crustal movements and monitoring plate boundary dynamics. The estimation of an accurate geodetic point velocity has therefore great importance in geosciences. In recent decades, comprehensive efforts have been put to determine the crustal velocity field 
in several scientific studies (NOCQUET \& CALAIS, 2003; D'ANASTASIO et al., 2006; HEFTY, 2008; WRIGHT \& WANG, 2010).

The artificial neural network (ANN) has been applied in diverse fields of geosciences and geoinformatics including velocity field determination and remarkable accomplishments were made with ANN. For example, a comparison of the ability of ANNs and polynomials have been put for modelling the crustal velocity field and ANN was offered as a suitable tool for modelling the velocity field (MOGHTASED-AZAR \& ZALETNYIK, 2009). A back propagation artificial neural networks (BPANN) was used for estimating the velocity of the geodetic densification points as an alternative tool to the interpolation methods and BPANN estimated the point velocities with a better accuracy than the interpolation methods (GULLU et al., 2011a). The utility of ANNs for estimating the velocities of the points in a regional geodetic network has been evaluated and the employment of BPANN is concluded as an alternative method for geodetic point velocity estimation (YILMAZ, 2012).

Deciding the number of hidden neurons required for the implementation of an arbitrary function is one of the major problems of ANN that still deserves further exploration. The main objective of this study is to evaluate BPANNs with different number of hidden neurons for optimizing the architecture of BPANN in estimating the velocities of GPS densification points. The point velocities that are estimated by BPANNs over a study area are compared, in terms of root mean square error (RMSE) of the velocity differences. The rest of this paper is structured as follows: The theoretical aspects of ANN, hidden number selection and training procedure are presented in Section 2. Section 3 outlines the study area, source data and evaluating methodology. The numerical case study is analyzed in Section 4. Section 5 includes the results and conclusions.

\section{ARTIFICIAL NEURAL NETWORKS}

ANN can be defined as physical cellular networks that are able to acquire, store, and utilize experiential knowledge related to network capabilities and performances (SINGH et al., 2010). ANN is formed by artificial neurons that are interlinked through synaptic weights for modelling of decision-making processes of a human brain. Each neuron receives inputs from other neurons and generates an output. The output acts as an input to other neurons. The input information of the neuron is manipulated by means of weights that are adjusted during an iterative adjustment process known as training process. ANN is a distributed parallel processor, consisting of simple units of processing with which knowledge can be stored and used for consecutive assessments (HAYKIN, 1999). ANN processes the records one at a time, and learns by comparing its prediction of the record with the known record. After the training procedure an activation function is applied to all neurons for generating the output information (LEANDRO \& SANTOS, 2007).

The multilayer perceptron (MLP) model that was suggested by Yilmaz (2012) for velocity field determination was selected for this study. Its advantages include 
easy implementation and generalization ability among several architectures of ANNs. MLP consists of one input layer with $N$ inputs, one (or more) hidden layer(s) with $q$ units and one output layer with $n$ outputs. The output of the model with a single output neuron (output layer represented by only one neuron, i.e. $n=1$ ) can be expressed by Nørgaard (1997):

$$
\mathrm{y}=\mathrm{f}\left(\sum_{j=1}^{q} W_{j} f\left(\sum_{l=1}^{N} w_{j, l} x_{l}+w_{j, 0}\right)+W_{0}\right)
$$

$W_{j}$ is the weight between the $j$-th hidden neuron and the output neuron, $w_{j, l}$ is the weight between the $l$-th input neuron and the $j$-th hidden neuron, $x_{l}$ is the $l$-th input parameter, $w_{j, 0}$ is the weight between a fixed input equal to 1 and $j$-th hidden neuron and $W_{o}$ is the weight between a fixed input equal to 1 and the output neuron.

The non-linear relationship between hidden and output layers requires an activation function, which can appropriately relate the corresponding neurons. The sigmoidal function that is used for satisfying the approximation conditions of ANNs (HAYKIN, 1999; BEALE at al., 2010) is selected as the activation function. The sigmoid function is mathematically represented by:

$$
\mathrm{f}(\mathrm{z})=1 /\left(1+e^{-z}\right)
$$

where $z$ is the input information of the neuron and $f(z) \in[0,1]$. The input and output values of ANN have to be scaled in this range. The proposed ANN for this study is trained using the classical back-propagation algorithm that has well-known ability as function approximators (PANDYA \& MACY, 1995). A standard tool in statistics known as cross-validation is used herein as a stopping criterion (HAYKIN, 1999) in which training, testing and validation data sets are needed. BPANN is currently the most widely used algorithm for connectionist learning. Its rapid rise in popularity has been a major factor in the resurgence of ANNs. Back-propagation is a nonlinear generalization of the squared error gradient descent learning rule for updating the weights of neurons in MLPs (SAVIO et al., 2010). Despite its limitations, backpropagation has expanded the range of problems to which ANNs can be applied (REZAI et al., 2009). BPANN has been more widely applied in engineering fields among all other ANN applications because of its capacity for nonlinear mapping, its accuracy for learning and its good robustness. BPANN is a feed forward and supervised learning network so it requires a desired response to be trained. BPANN learns how to transform inputs into desired responses, so it is widely used for function approximation. The major purpose of developing function approximation is to interpolate in a meaningful way between the training samples (HOLMSTROM \& 
KOISTINEN, 1992), in order to generalize a model from existing training data and make predictions for the novel data (LIU \& STARZYK, 2008).

There are two major challenges regarding the hidden layers while using BPANN: (a) The number of hidden layers and (b) how many neurons will be in each of these hidden neurons. Two hidden layers are required for modelling data with discontinuities such as a saw tooth wave pattern. Using two hidden layers rarely improves ANN, and it may introduce a greater risk of converging to a local minima. In fact, for nearly all problems, one hidden layer is sufficient (PANCHAL et al., 2011). The architecture of standard three-layer BPANN that is composed of input layer, one hidden layer with sigmoid neurons and output layer with linear neurons is utilized in this study. Each layer contains different number of neurons in accordance with the problem in question (ZHANG et al., 1998). It is well-known that, a network with one hidden layer can approximate any continuous function given a sufficient number of hidden neurons (CYBENKO, 1989; FUNAHASHI, 1989; HORNIK et al., 1989; BISHOP, 1995). The architecture of a simple BPANN is shown in Figure 1.

Figure 1 - The BPANN architecture.

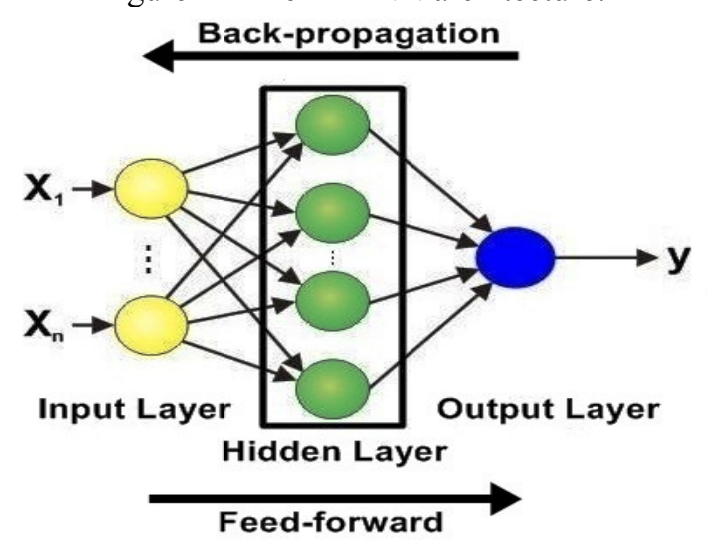

\subsection{The Number of Hidden Neurons}

The number of neurons in the hidden layer is an important part of overall BPANN architecture. Though these layers do not directly interact with the external environment, they have a significant influence on the final output (PANCHAL et al., 2011). In most of the reported applications, the number of hidden neurons is determined through a trial and error process (i.e. Yilmaz (2012), Karimi et al. (2013)). Very often, several arbitrary structures are tried and the one giving the best performance is selected. The number of hidden neurons must be carefully considered on the basis of experience. The method usually results in the lack or redundancy of hidden neurons. Too many hidden neurons may lead to overfitting of 
data and poor generalization, while too few hidden neurons may not allow BPANN to learn the data sufficiently and accurately.

There are various approaches to find the optimal structure of ANN with an optimal size of the hidden neuron in a constructive or destructive algorithm. During the constructive/destructive processes, the number of hidden neurons are increased or decreased incrementally. In these methods, the available data are divided usually into three independent sets: A training set, a testing set and a validation set. Only the training set participates in the ANN learning, the testing set is used to avoid overfitting and the validation set is used to compute prediction error, which approximates the generalization error. The performance of a function approximation during training, testing and validation is measured, respectively, by training error, testing error and validation error presented in the form of mean squared error (MSE) (LIU \& STARZYK, 2008). For a given set of $N$ inputs, MSE is defined by:

$$
\mathrm{MSE}=1 / N \sum_{i=1}^{N}\left(y_{i}{ }^{\text {act }}-y_{i}{ }^{\text {pred }}\right)^{2}
$$

where $y_{i}^{a c t}$ denotes the given actual output value and $y_{i}^{\text {pred }}$ denotes the neural network (predicted) output.

In this study, a destructive algorithm (LE CUN, 1990; REED, 1993; LAAR \& HESKES, 1999; LIANG, 2007) is applied starting with 30 neurons in the hidden layer of BPANN and after the training process has taken place, BPANN is pruned from 30 to 2 by decreasing the hidden neurons in pairs. Some existing methods for selecting the number of hidden neurons mentioned below are also used for comparing the results.

\subsubsection{Methods for Selecting the Number of Hidden Neurons}

There are some existing methods that are currently used in the field of neural networks to choose the architecture of ANN. Some of the approaches have a theoretical formulation behind and some of them are just justified based on experience. These methods were used in the experimental study without a preliminary preference. The following notation is used: $N$ is the dimension of the input data, $N h$ represents the number of hidden neurons in the single hidden layer and $M$ is used for the output dimension. $T$ is used to indicate the number of available training vectors.

1) Baily and Thompson (1990) have submitted that $N_{h}=N * 0.75$.

2) Katz (1992) proposed ANN architecture with $N * 1.5 \leq N_{h} \leq N * 3$.

3) Aldrich et al. (1994) used the following equation for the number of hidden neurons. $N_{h}=T / k(N+M),(2 \leq \mathrm{k}<10)$. 
4) Barron (1994) pointed out that the number of hidden neurons was $N_{h}=$ $\sqrt{T /\left(N^{*} \log T\right)}$.

5) Kaastra and Boyd (1996) have suggested to use $N_{h}=\sqrt{N^{*} M}$ hidden neurons in ANN architecture.

6) Kanellopoulas and Wilkinson (1997) estimated the number of hidden neurons by $N_{h}=N * 2$.

7) Neuralware (2001) defined ANN structure with $N_{h}=T /\left(5^{*}(N+M)\right)$ hidden neurons.

8) Witten and Frank (2005) estimated the default ANN architecture size as $N_{h}=(N+M) / 2$.

\subsection{BPANN Training Procedure}

Training of BPANN, implemented to find a good mapping function, can be done by an adjustment of the weights between the hidden layer and the output layer to the data set that attempts to decrease the residuals (difference between the computed output and the actual given output) of the output of the neural network using a suitable supervised learning algorithm while fixing the network architecture and activation function. Through the process of training, BPANN learns general properties of the input - output relationship of a system and thus generalizes beyond training data points (MAHMOUDABADI et al., 2009). The training procedure consists of two main steps: Feed-forward and back-propagation. The training process continues over the training data set for several thousand epochs. The delta rule based on squared error minimization is used for BPANN training procedure. BPANN is trained to minimize the MSE by a gradient method.

\section{STUDY AREA, SOURCE DATA AND METHODOLOGY}

In this study, the densification point velocity estimation is carried on over a study area that is located in internal western region of Turkey within the geographical boundaries: $37.85^{0} \mathrm{~N} \leq \varphi \leq 39.78^{0} \mathrm{~N} ; 29.11^{0} \mathrm{E} \leq \lambda \leq 30.23{ }^{0} \mathrm{E}$ defining approximately area of $65000 \mathrm{~km}^{2}(\sim 230 \mathrm{~km} \mathrm{x} \sim 280 \mathrm{~km})$.

The evaluating tests of the densification points' velocity refer to a source data set in the study area (Figure 2). The source data set comprises 44 existing GPS sites that belong to Turkish National Fundamental GPS Network (TNFGN) and it is separated into three groups for training, testing and validation procedures. The velocities of TNFGN points used in this study for evaluating BPANN based point velocities, were computed in ITRF2000 (reference epoch 2005.00) with repeated GPS observations that relates positional precision at sub-millimetre level.

The evaluation is based on the determination of the differences between the known point velocity and the point velocities estimated by BPANN, using the equation below.

$$
\Delta \mathrm{V}_{\mathrm{X}, \mathrm{Y}, \mathrm{Z}}=\mathrm{V}_{(\text {(known) }}-\mathrm{V}_{\text {(estimated) }}
$$


where $\Delta V_{X, Y, Z}$ is the point velocity residual, $V_{(\text {known })}$ is the point velocity known through GPS observations and $V_{\text {(estimated) }}$ is the point velocity based on BPANN. The point velocity residuals are investigated by root mean square error (RMSE) value because RMSEs are sensitive to even small errors, which is good for comparing small differences between estimated and known discharges on models (GULLU et al., 2011b) and RMSEs are effective tools for evaluating the results of ANN applications (YILMAZ, 2012). RMSE is defined by:

$$
\operatorname{RMSE}=\sqrt{\frac{1}{n} \sum_{i=1}^{n}\left(\Delta V i_{X, Y, Z}\right)^{2}}
$$

Figure 2 - Geographical point distribution over the study area.
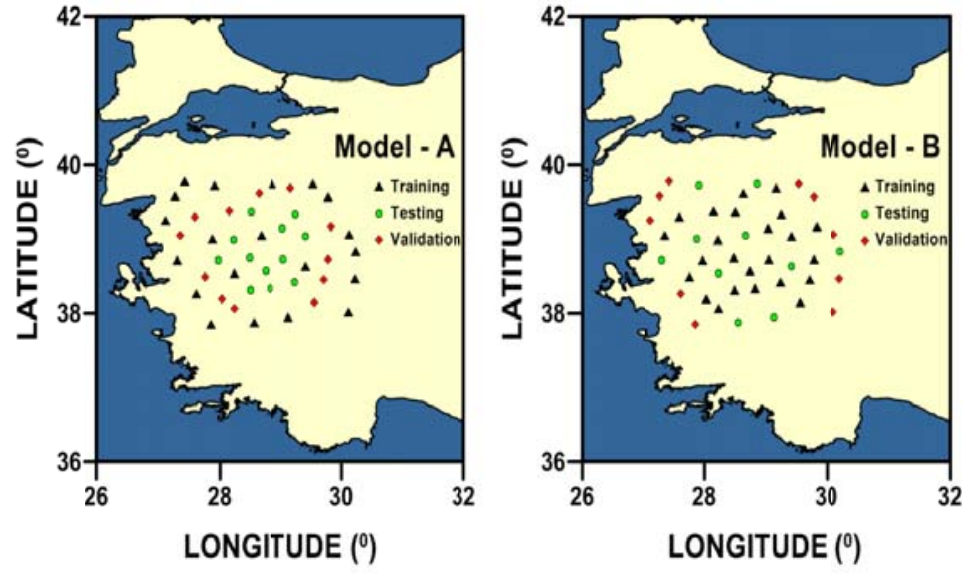

\section{EXPERIMENTAL STUDY}

The source data set is divided into three subsets. 20 TNFGN points are selected as training data from the source data set and remaining 24 TNFGN points that can be considered as densification points are used as 12 points $(50 \%)$ for testing and 12 points $(50 \%)$ for validation, in Model A. The training data are swapped with testing and validation data in Model B and 44 TNFGN points are used as training, testing and validation data consisting of 24,10 and 10 points, respectively (Figure 2). The division is done-keeping in mind that each subset should be representative of all possible variations in the dataset. BPANN that developed for this study has two neurons in the input layer and one neuron in the output layer. The geographical coordinates (latitude and longitude) of the point are selected as input quantities and each velocity component of the point $\left(\mathrm{V}_{\mathrm{X}, \mathrm{Y}, \mathrm{Z}}\right.$, respectively) is used as output 
quantity for training and testing procedure of BPANN. The training process was carried out with a sufficiently large number of hidden neurons. In our simulations, 30 hidden neurons are used as a starting value. A sufficiently large number of hidden neurons are required because too few hidden neurons often give a large first singular value, which, together with a high threshold, provide an incorrect indication of the rank of the output activations of the hidden layer neurons (TEOH et al., 2006).

BPANN developed in MATLAB's artificial neural network module allows to dynamically changing the parameters of a learning algorithm, to monitor error values and weight changes, and to generate digital data and graphs that show whether learning is sufficient. BPANN [2:30:1] (2 source nodes in the input layer, 30 neurons in the hidden layer and 1 neuron in the output layer) is trained for 100000 epochs to find an optimal set of connection weights. The velocities of the testing points are estimated via trained BPANN to minimize overfitting and the velocity estimation (generalization) power of the resultant BPANN is assessed by the velocities of the validation points. The parameters that are obtained in the training procedure with 30 hidden neurons are fixed and used in the training process of pruned BPANNs. Pruning of BPANN is applied after the training procedure. The number of hidden neurons is subsequently decreased in pairs from 30 to 2 . These pruned BPANNs are retrained by fixed parameters and applied on the testing and validation data sets. Furthermore, BPANN architectures with 1,3 and 5 hidden neurons are used for evaluating with respect to the existing methods mentioned above (Model $\mathrm{A} \rightarrow N=2, M=1, T=20$; Model $\mathrm{B} \rightarrow N=2, M=1, T=24$ ).

The significance of pruning away hidden neurons in BPANN architecture is investigated by RMSE values of the velocity residuals $\left(\Delta V_{X, Y, Z}\right)$ of the training, testing and validation points (Figure 3 in appendix). The minimum and maximum values of these RMSEs and the corresponding hidden neuron numbers are summarized in Table 1, in appendix.

The reference velocity fields $\left(V_{X, Y, Z}\right)$ of the study area that are generated from GPS observations and the velocity residual $\left(\Delta V_{X, Y, Z}\right)$ maps with regard to the smallest velocity differences of the testing and validation points (associated with 20 hidden neurons) computed by equation (4), are given in Figure 4, in appendix. The contour lines are drawn at 2-mm intervals on the velocity residual maps.

\section{RESULTS AND CONCLUSIONS}

The analysis of the RMSE values given in Appendix, Figure 3 reveals that the training data set, the testing data set and the validation data set are very similar. The differences between the RMSE values based on the training points, the testing points and the validation points are quite small. It can be considered that the training data set represents the possible variations in the study area well.

Table 1, in Appendix, shows that for each data set, RMSE values of Model A are in better agreement than Model B. It can be seen that Model A produced a larger error on the training data set than Model B. However, the results of the testing and 
validation data sets are better in Model A. This suggests that the training data set of Model A was representative of the entire data source (testing and validation data sets) and Model A produced RMSE values that were consistent for training, testing and validation data sets.

The graphical presentations in Appendix, Figure 3 confirms that BPANN architectures provide the sufficient RMSE values of the point velocity residual that relates the sufficient positional accuracy for the source data $( \pm 3 \mathrm{~cm}$ for TNFGN points).

The objective of this study was to quantify the significance of removing away hidden neurons in BPANN architecture for estimating the densification point velocity. From the results of this study, the following remarks can be made:

(1) The employment of BPANN with 30 hidden neurons did not lead an overfitting of data nor poor generalization. 30 hidden neurons is an acceptable value for starting removal processes of hidden neurons.

(2) Hidden neurons between 30 and 20 did not have a marginal effect on the resulting performance of BPANN.

(3) In Model A and Model B, minimum RMSE values (Model $\mathrm{A} \rightarrow \pm 1.4, \pm 0.7$, $\pm 1.4 \mathrm{~mm} /$ year; Model $\mathrm{B} \rightarrow \pm 1.5, \pm 1.3, \pm 1.4 \mathrm{~mm} /$ year, respectively) of the training point velocity residuals are obtained by BPANN with 20 hidden neurons such as submitted by Gullu et al. (2011a) and by Yilmaz (2012).

(4) In Model A, sufficient RMSE values $( \pm 2.3, \pm 1.3, \pm 1.7 \mathrm{~mm} /$ year for the testing points; $\pm 2.0, \pm 1.2, \pm 1.7 \mathrm{~mm} /$ year for the validation points, respectively) are estimated when 20 hidden neurons are used for BPANN architecture, with respect to the training set results.

(5) In Model B, minimum RMSE values $( \pm 2.6, \pm 1.3, \pm 1.9 \mathrm{~mm} /$ year for the testing points; $\pm 2.7, \pm 1.3, \pm 1.8 \mathrm{~mm} /$ year for the validation points, respectively) are obtained by BPANN with 20 hidden neurons.

(6) The velocity residual $\left(\Delta V_{X, Y, Z}\right)$ maps in Appendix, Figure 4 clarify that BPANN architecture with 20 hidden neurons is effective for geodetic velocity field determination with a satisfactory positional accuracy.

(7) In Model A, BPANN with 2 hidden neurons provided the smallest RMSE values $( \pm 2.0, \pm 1.2, \pm 1.7 \mathrm{~mm} /$ year for the testing points, respectively) of the velocity residuals (associated with $\left.\Delta V_{X, Y, Z}\right)$ and $( \pm 1.8, \pm 1.2 \mathrm{~mm} /$ year for the validation points, respectively) of the velocity residuals (associated with $\Delta V_{X, Y}$ ). For the training data set, RMSE values $( \pm 1.7, \pm 1.1, \pm 1.6 \mathrm{~mm} /$ year, respectively) are obtained by the same BPANN architecture.

(8) Maximum RMSE values of the velocity residuals for all three data sets are obtained by BPANN with 1 hidden neuron in Model A and Model B. These results show that BPANN could not learn the source data sufficiently and accurately when the number of hidden neurons is $1\left(N_{h}<N\right)$.

In conclusion, the employment of BPANN estimates the densification point velocities with a sufficient accuracy. The destructive algorithm can be used for optimizing the number of neurons used in the hidden layer of BPANN that will be 
used in velocity field determination. 20 hidden neurons can be accepted as a starting value in the pruning approach with a training set that distributes throughout the study are in all dimensions (representative of the testing and validation data sets). Furthermore, a rough guideline of appropriate number of hidden neurons can be introduced as $N_{h} \leq T$ with respect to the accuracy of the result and the learning time for adaptation of BPANN for estimating the geodetic point velocities, determining velocity field in locations where future GPS stations could be deployed and interpolating the velocity field in areas that will not be instrumented.

\section{ACKNOWLEDGEMENTS}

The author thanks the two anonymous reviewers for their constructive comments to the paper.

\section{REFERENCES}

ALDRICH, C.; VAN DEVENTER, J.S.J.; REUTER, M.A. The application of neural nets in the metallurgical industry, Minerals Engineering, 7, 793-809, 1994.

BAILEY, D.L.; THOMPSON, D.M. Developing neural-network applications, AI Expert, 5 (9), 34-41, 1990.

BARRON, A.R. Approximation and estimation bounds for artificial neural networks, Machine Learning, 14 (1), 115-133, 1994.

BEALE, M.H.; HAGAN, M.T.; DEMUTH, H.B. Neural Network Toolbox 7 User's Guide. The MathWorks Inc., Natick, MA, 951 pp., 2010.

BISHOP, C.M. Neural networks for pattern recognition, Oxford University Press, New York, NY, 482 pp., 1995.

CYBENKO, G. Approximations by superpositions of sigmoidal functions, Mathematics of Control, Signals and Systems, 2 (4), 303-314, 1989.

D'ANASTASIO, E.; DE MARTINI, P.M.; SELVAGGI, G.; PANTOSTI, D.; MARCHIONI, A.; MASEROLI, R. Short-term vertical velocity field in the Apennines (Italy) revealed by geodetic levelling data, Tectonophysics, 418, 219-234, 2006.

FERLAND, R.; ALTAMIMI, Z.; BRUYNINX, C.; CRAYMER, M.; HABRICH, H.; KOUBA, J. Regional networks densification, IGS Workshop Towards Real-Time, Ottawa, Canada, pp. 123-132, 2002.

FUNAHASHI, K. On the approximate realization of continuous mappings by neural networks, Neural Networks, 2, 183-192, 1989.

GULLU, M.; YILMAZ, I.; YILMAZ, M.; TURGUT, B. An alternative method for estimating densification point velocity based on back propagation artificial neural networks, Studia Geophysica et Geodaetica, 55 (1), 73-86, 2011 a.

GULLU, M.; YILMAZ, M.; YILMAZ, I. Application of back propagation artificial neural network for modelling local GPS/levelling geoid undulations: A comparative study, FIG Working Week 2011, 18-22 May, Marrakech, Morocco, 2011b.

Bol. Ciênc. Geod., sec. Artigos, Curitiba, v. 19, no 4, p.558-573, out-dez, 2013. 
HAYKIN, S. Neural networks: A comprehensive foundation, Prentice Hall, Upper Saddle River, NJ, 842 pp., 1999.

HEFTY, J. Densification of the central Europe velocity field using velocities from local and regional geokinematical projects, Geophysical Research Abstracts, 10 (EGU2008-A-01735), 2008.

HOLMSTROM, L.; KOISTINEN, P. Using additive noise in back-propagation training, IEEE Transactions on Neural Networks, 3 (1), 24-38, 1992.

HORNIK, K.; STINCHCOMBE, M.; WHITE, H. Multilayer feedforward networks are universal approximators, Neural Networks, 2, 359-366, 1989.

KAASTRA, I.; BOYD, M. Designing a neural network for forecasting financial and economic time series, Neurocomputing, 10, 215-236, 1996.

KANELLOPOULAS, I., WILKINSON, G.G. Strategies and best practice for neural network image classification, International Journal of Remote Sensing, 18 (4), 711-725, 1997.

KARIMI, S.; KISI, O.; SHIRI, J.; MAKARYNSKYY, O. Neuro-fuzzy and neural network techniques for forecasting sea level in Darwin Harbor, Australia, Computers and Geosciences, 52, 50-59, 2013.

KATZ, J.O. Developing neural network forecasters for trading, Technical Analysis of Stocks and Commodities, 10 (4), 160-168, 1992.

LAAR, P.V.D.; HESKES, J. Pruning using parameter and neuronal metrics, Neural Computation, 11, 977-993, 1999.

LEANDRO, R.F.; SANTOS, M.C. A neural network approach for regional vertical total electron content modelling, Studia Geophysica et Geodaetica, 51 (2), 279-292, 2007.

LE CUN, Y.; DENKER, J.; SOLLA, S.; HOWARD, R.E.; JACKEL, L.D. Optimal brain damage, In: TOURETZKY, D.S. (Ed.), Advances in Neural Information Processing Systems II, Morgan Kauffman, San Francisco, CA, pp. 598-605, 1990.

LIANG, X. Removal of hidden neurons in multilayer perceptrons by orthogonal projection and weight crosswise propagation, Neural Computing and Applications, 16, 57-68, 2007.

LIU, Y.; STARZYK, J.A. Optimized approximation algorithm in neural networks without overfitting, IEEE Transactions on Neural Networks, 19 (6), 983-995, 2008.

MAHMOUDABADI, H.; IZADI, M.; MENHAJ, M.B. A hybrid method for grade estimation using genetic algorithm and neural networks, Computers and Geosciences, 13, 91-101, 2009.

MOGHTASED-AZAR, K.; ZALETNYIK, P. Crustal velocity field modelling with neural network and polynomials, In: SIDERIS, M.G. (Ed.), Observing our changing Earth, International Association of Geodesy Symposia, 133, pp. 809816, 2009.

NEURALWARE INC. The reference guide, Pittsburgh, PA, 2001. http://www .neuralware.com [Accessed 10.04.2013]. 
NOCQUET, J.M.; CALAIS, E. Crustal velocity field of western Europe from permanent GPS array solutions, 1996-2001, Geophysical Journal International, 154, 72-88, 2003.

NØRGAARD, M. Neural Network Based System Identification Toolbox, Technical Report 97-E-851, Department of Automation Technical University of Denmark, Copenhagen, Denmark, 31 pp., 1997.

PANCHAL, G.; GANATRA, A.; KOSTA, Y.P.; PANCHAL, D. Behaviour analysis of multilayer perceptrons with multiple hidden neurons and hidden layers, International Journal of Computer Theory and Engineering, 3 (2), 332-337, 2011.

PANDYA, A.S.; MACY, R.B. Pattern recognition with neural networks in C++, CRC Press, Boca Raton, Florida, 410 pp., 1995.

REED, R. Pruning algorithms - a survey, IEEE Transactions on Neural Networks, 4 (5), 740-747, 1993.

REZAEI, K.; GUEST, B.; FRIEDRICH, A.; FAYAZI, F.; NAKHAEI, M.; BEITOLLAHI, A.; FATEMI-AGHDA, S.M. Feed forward neural network and interpolation function models to predict the soil and subsurface sediments distribution in Bam, Iran, Acta Geophysica, 57 (2), 271-293, 2009.

SAVIO, A.; CHARPENTIER, J.; TERMENON, M.; SHINN, A.K.; GRANA, M. Neural classifiers for schizophrenia diagnostic support on diffusion imaging data, Neural Network World, 20 (7), 935-950, 2010.

SINGH, N.; SINGH, T.N.; AVYAKTANAND, T.; KRIPA, M.S. Textural identification of basaltic rock mass using image processing and neural network, Computers and Geosciences, 14, 301-310, 2010.

TEOH, E.J.; TAN, K.C.; XIANG, C. Estimating the number of hidden neurons in a feedforward network using the singular value decomposition, IEEE Transactions on Neural Networks, 17 (6), 1623-1629, 2006.

TURKISH CHAMBER OF SURVEY AND CADASTRE ENGINEERS. Large scale map and map information Production regulation [in Turkish], Iskur Press, Ankara, 260 pp., 2008.

WITTEN, I.H.; FRANK, E. Data mining: Practical machine learning tools and techniques, Morgan Kaufmann, San Francisco, CA, 560 pp., 2005

WRIGHT, T., WANG, H. Large-scale crustal velocity field of western Tibet from InSAR and GPS reveals internal deformation of the Tibetan plateau, Geophysical Research Abstracts, 12 (EGU2010-7092), 2010.

YILMAZ, M. The Utility of Artificial Neural Networks in Geodetic Point Velocity Estimation [in Turkish], Ph.D. Dissertation, Afyon Kocatepe University, Afyonkarahisar, Turkey, 106 pp., 2012.

ZHANG, G.; PATUWO, B.E.; HU, M.Y. Forecasting with artificial neural networks: The state of the art, International Journal of Forecasting, 14, 35-62, 1998.

(Recebido em maio de 2013. Aceito em julho de 2013).

Bol. Ciênc. Geod., sec. Artigos, Curitiba, v. 19, no 4, p.558-573, out-dez, 2013. 


\section{APPENDIX}

Figure 3 - RMSE values of the training, testing and validation data sets.
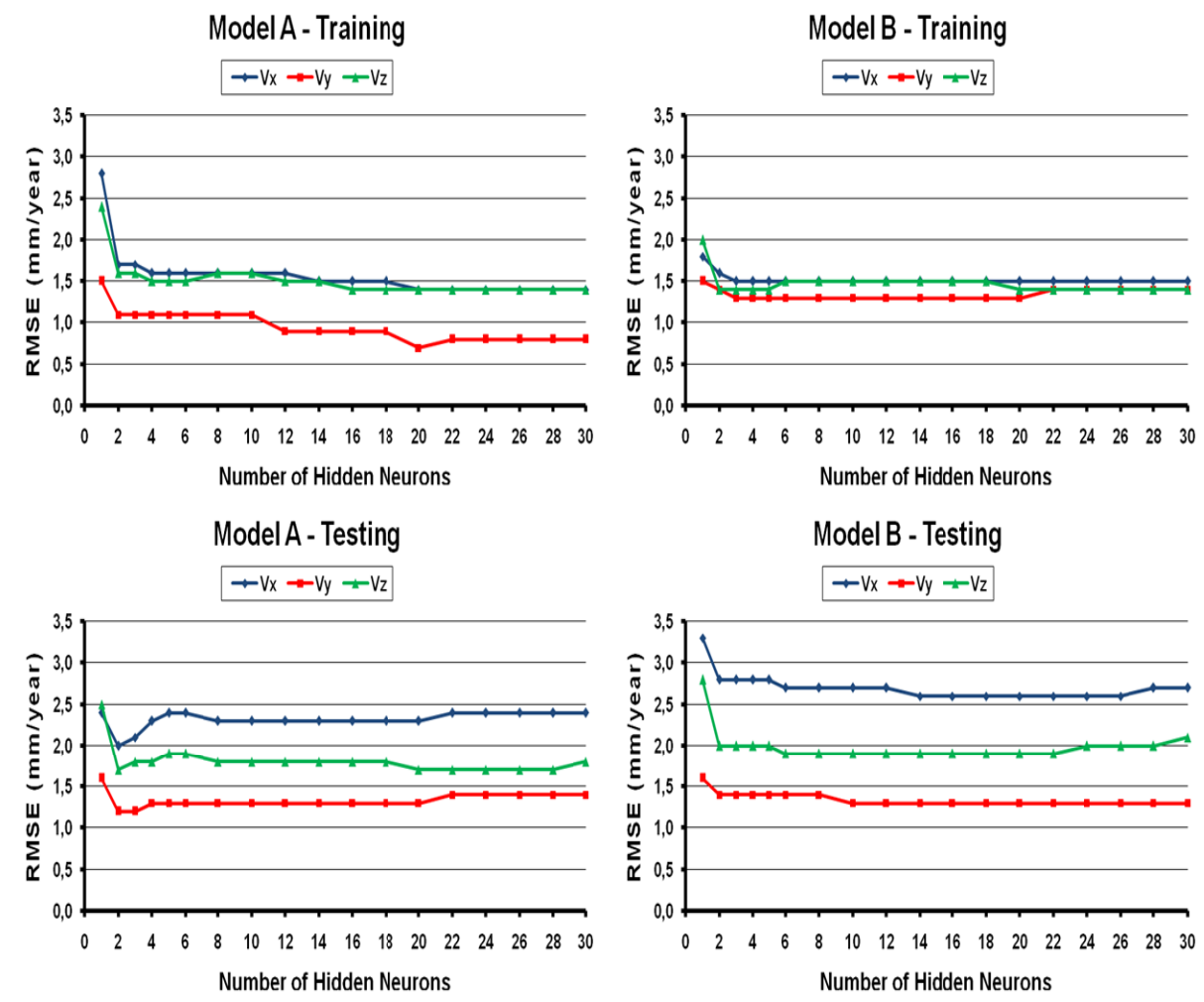

Model A - Validation
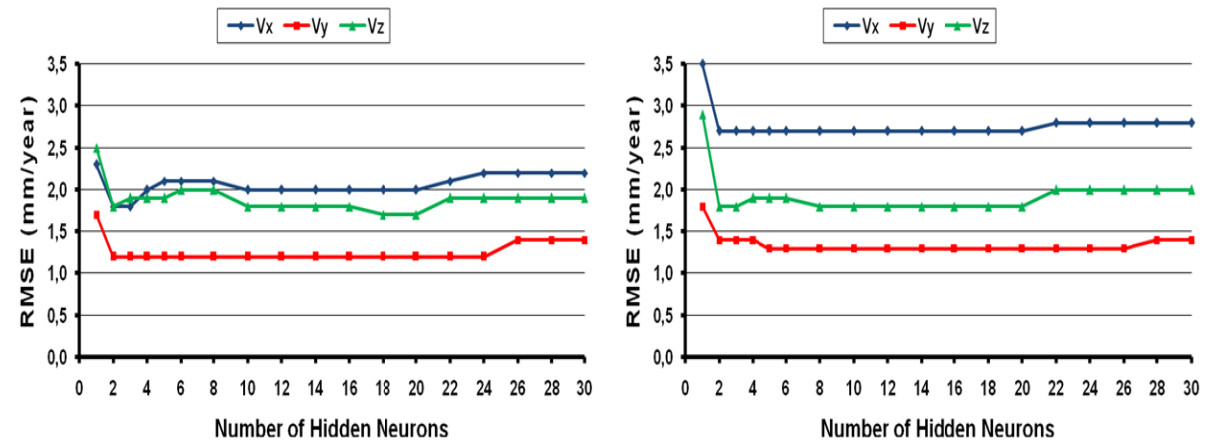

Bol. Ciênc. Geod., sec. Artigos, Curitiba, v. 19, n 4, p.558-573, out-dez, 2013. 
Table 1 - The minimum and maximum values of RMSEs (in mm/year).

\begin{tabular}{|c|c|c|c|c|}
\hline \multicolumn{2}{|r|}{ Data Set } & \multirow{2}{*}{$\frac{\text { Velocity }}{\Delta \mathrm{Vx}}$} & \multirow{2}{*}{$\begin{array}{c}\text { Min / Neuron } \\
1.4 / 20\end{array}$} & \multirow{2}{*}{$\begin{array}{c}\text { Max / Neuron } \\
2.8 / 1\end{array}$} \\
\hline \multirow{9}{*}{ 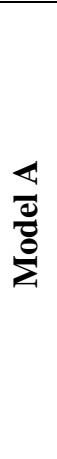 } & \multirow{3}{*}{ Training } & & & \\
\hline & & $\Delta \mathrm{Vy}$ & $0.7 / 20$ & $1.5 / 1$ \\
\hline & & $\Delta \mathrm{Vz}$ & $1.4 / 20$ & $2.4 / 1$ \\
\hline & \multirow{3}{*}{ Testing } & $\Delta \mathrm{Vx}$ & $2.0 / 2$ & $2.4 / 1$ \\
\hline & & $\Delta \mathrm{Vy}$ & $1.2 / 2$ & $1.6 / 1$ \\
\hline & & $\Delta \mathrm{Vz}$ & $1.7 / 2$ & $2.5 / 1$ \\
\hline & \multirow{3}{*}{ Validation } & $\Delta \mathrm{Vx}$ & $1.8 / 2$ & $2.3 / 1$ \\
\hline & & $\Delta \mathrm{Vy}$ & $1.2 / 2$ & $1.7 / 1$ \\
\hline & & $\Delta \mathrm{Vz}$ & $1.7 / 20$ & $2.5 / 1$ \\
\hline \multirow{9}{*}{ 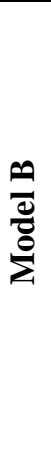 } & \multirow{3}{*}{ Training } & $\Delta \mathrm{Vx}$ & $1.5 / 20$ & $1.8 / 1$ \\
\hline & & $\Delta \mathrm{Vy}$ & $1.3 / 20$ & $1.5 / 1$ \\
\hline & & $\Delta \mathrm{Vz}$ & $1.4 / 20$ & $2.0 / 1$ \\
\hline & \multirow{3}{*}{ Testing } & $\Delta \mathrm{Vx}$ & $2.6 / 20$ & $3.3 / 1$ \\
\hline & & $\Delta \mathrm{Vy}$ & $1.3 / 20$ & $1.6 / 1$ \\
\hline & & $\Delta \mathrm{Vz}$ & $1.9 / 20$ & $2.8 / 1$ \\
\hline & \multirow{3}{*}{ Validation } & $\Delta \mathrm{Vx}$ & $2.7 / 20$ & $3.5 / 1$ \\
\hline & & $\Delta \mathrm{Vy}$ & $1.3 / 20$ & $1.8 / 1$ \\
\hline & & $\Delta \mathrm{Vz}$ & $1.8 / 20$ & $2.9 / 1$ \\
\hline
\end{tabular}

Bol. Ciênc. Geod., sec. Artigos, Curitiba, v. 19, no 4, p.558-573, out-dez, 2013. 
Figure 4 - Reference velocity fields and residual velocity maps of the study area.
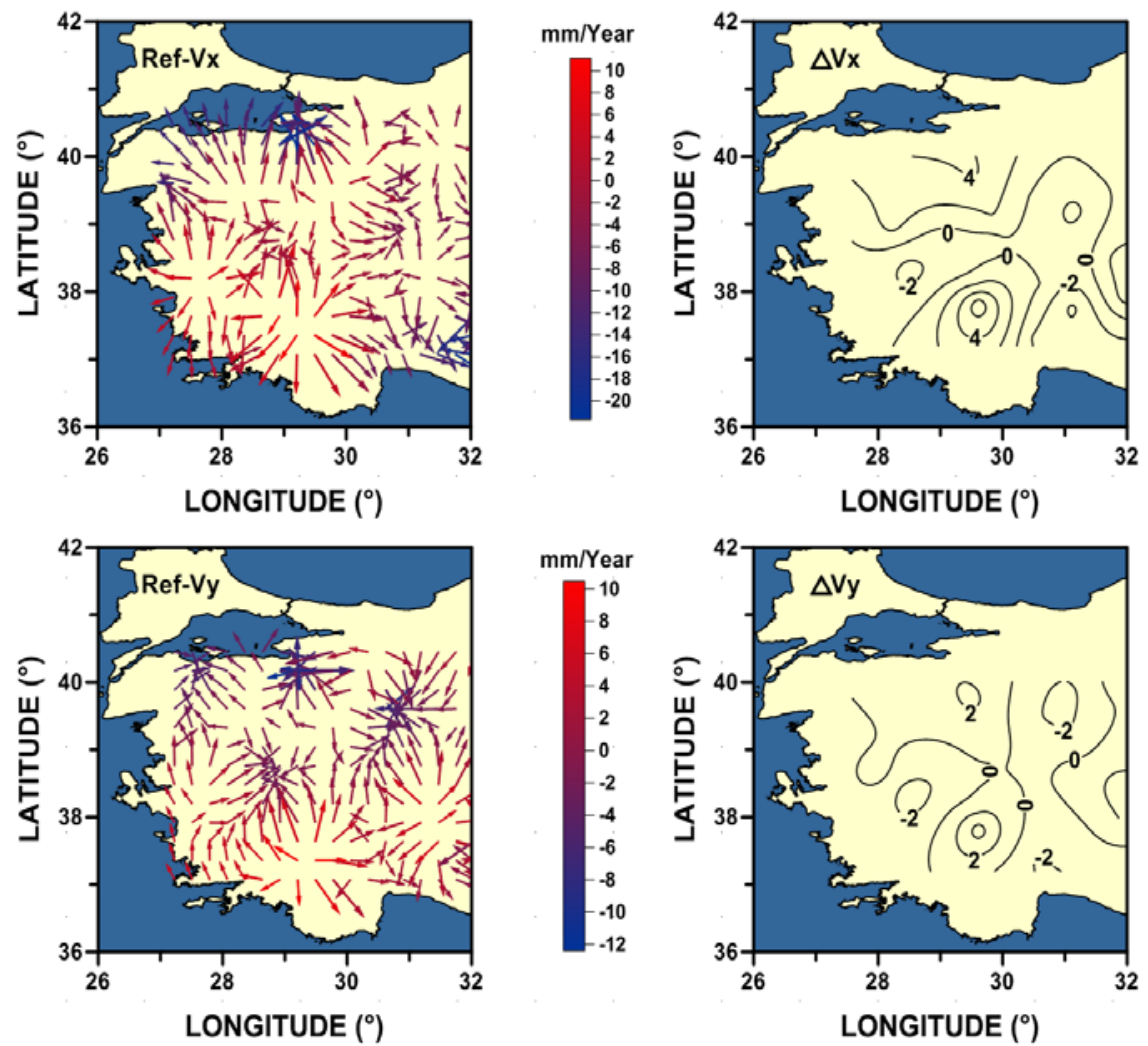

$\mathrm{mm} /$ Year
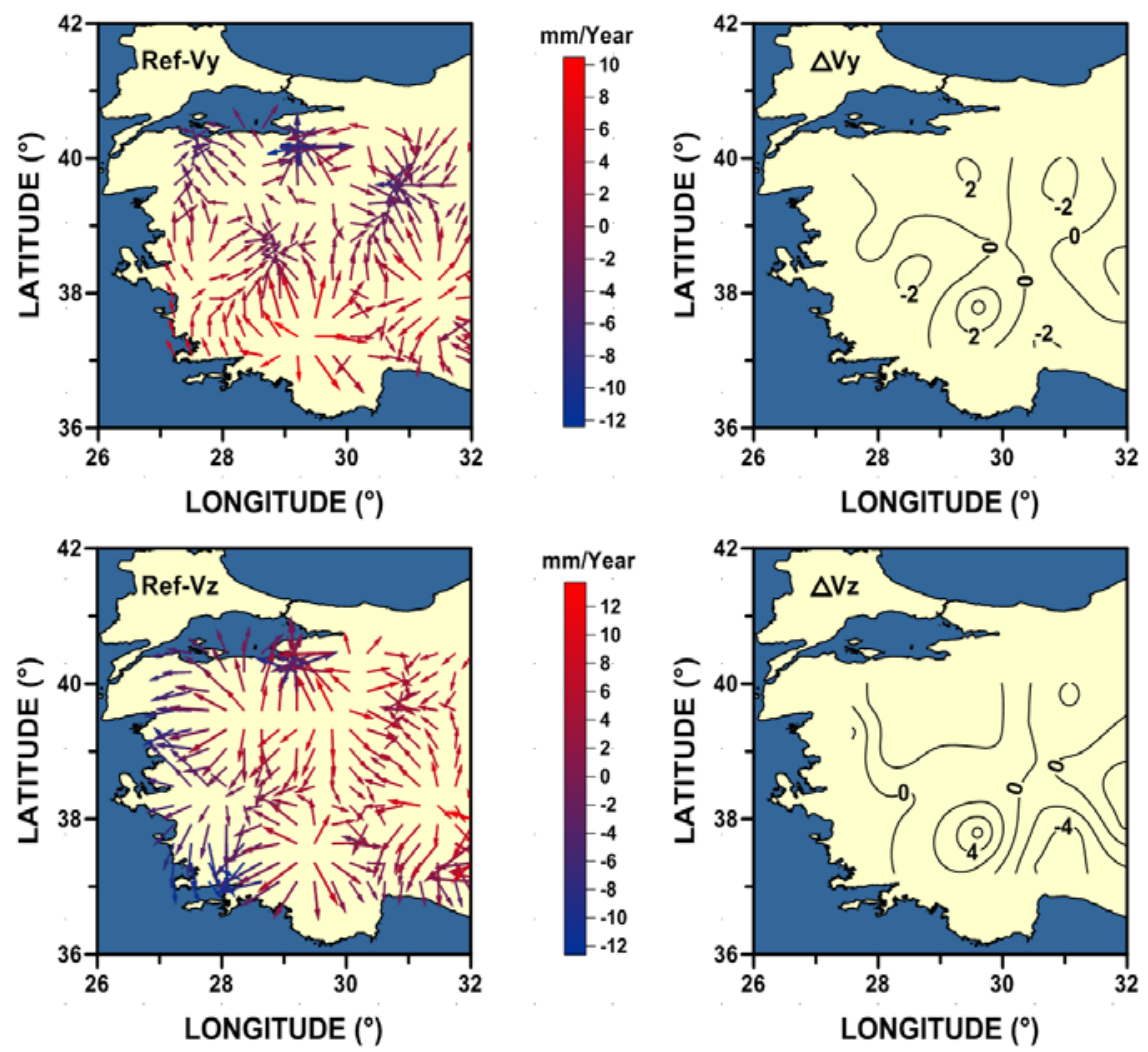

Bol. Ciênc. Geod., sec. Artigos, Curitiba, v. 19, no 4, p.558-573, out-dez, 2013. 